\title{
EFFECTS OF HAMO NK HARD CAPSULE ON SERUM LIPID PROFILES IN DYSLIPIDEMIA EXPERIMENTAL ANIMALS
}

\author{
Pham Thuy Phuong1, Pham Quoc Binh1, Dinh Thi Hong Minh1, Tran Thi Thu Hien', \\ Nguyen Trong Thong ${ }^{3}$, Pham Thi Van Anh² and Dang Thi Thu Hien ${ }^{2, \bigotimes}$ \\ ${ }^{1}$ Vietnam University of Traditional Medicine, \\ ${ }^{2}$ Hanoi Medical University, \\ ${ }^{3}$ Phenikaa University
}

Dyslipidemia is a major risk factor for cardiovascular disease. Polyherbal formulation is a traditional therapeutic strategy used to treat dyslipidemia over many years of tradition. The aim of this study was designed to evaluate the effects of Hamo NK hard capsule on endogenous dyslipidemia and exogenous dyslipidemia experimental animal model. In endogenous hyperlipidemia model, mice were previously treated by Hamo NK hard capsule, and intraperitoneally injected by poloxamer - 407 to induce hyperlipidemia. Rats were oral administration of oil - cholesterol mixture and Hamo NK for 4 consecutive weeks (exogenous dyslipidemia). Parameters of serum lipid were determined. Hamo NK ameliorated the elevation of serum total cholesterol, Non - HDL - cholesterol at the daily dose of $1.5 \mathrm{~g} / \mathrm{kg}$ b.w $(p<0.05)$. Also, there was no signicant difference in increase on high - density lipoprotein cholesterol levels and decrease triglyceride levels between the groups. Hamo NK at two doses of $0.25 \mathrm{~g} / \mathrm{kg} \mathrm{b.w}$ and $0.75 \mathrm{~g} / \mathrm{kg} \mathrm{b.w} \mathrm{significantly} \mathrm{reduced} \mathrm{serum} \mathrm{LDL} \mathrm{-} \mathrm{C} \mathrm{levels} \mathrm{compared} \mathrm{to} \mathrm{the}$ cholesterol control group. Hamo NK hard capsule affected on serum lipid modulations in dyslipidemia models.

Keywords: Hamo NK, dyslipidemia, serum lipid levels.

\section{INTRODUCTION}

Polyherbal formulation is a traditional therapeutic strategy that takes advantage of the combination of several medicinal herbs to achieve enhanced therapeutic effects against a disease. ${ }^{1}$ The use of herbal medicines is globally increasing tremendously and about $8 \%$ of the world population rely on it for some part of their primary healthcare. ${ }^{2}$ Dyslipidemia refers to excess status of fatty substances including cholesterol, triglyceride and decreased high density lipoprotein cholesterol (HDL - C) in the bloodstream. ${ }^{3}$ Besides, dyslipidemia is a notable risk factor for the development of cardiovascular

Corresponding author: Dang Thi Thu Hien,

Hanoi Medical University

Email: thuhien2629@gmail.com

Received: 22/12/2020

Accepted: 08/03/2021 disease (CVD), which is the main cause of mortality worldwide, one of the most important risk factors for cardiovascular diseases (CVD) such as atherosclerosis, myocardial infarction, and cerebral vascular accidents.

At present, statins, such as simvastatin, atorvastatin, rosuvastatin...are the most commonly used lipid - lowering drugs, as they efficiently reduce plasma lipids; however, they also present a number of undesirable side effects, such as hepatotoxicity, rhabdomyolysis and skeletal muscle injury, which have limited their usage. ${ }^{4}$ Therefore, it is necessary to identify and develop effective, and natural agents that may be valuable in regulating lipid metabolism. In recent years, traditional Vietnamese medicine has attracted greater attention in metabolic syndrome treatments, and has become a common therapy for controlling 
symptoms in patients with dyslipidemia.

Hamo NK hard capsule is written by a deceased herbalist Nguyen Kieu. The formula used to prepare the hard capsule is Pericarpium Citri reticulatae perenne, Rhizoma Smilax ferox, Radix Achyranthis bidentatae, Rhizoma Imperatae cylindricae, Semen Cassiae torae, Flos Styphnolobii japonici imaturi, Folium Nelumbinis nuciferae, Spica Prunellae, Rhizoma Typhonium trilobatum. A number of previous studies have shown the beneficial of some herbal medicines in reducing serum lipid levels. ${ }^{5,6,7}$ Therefore, to provide scientific evidence of its efficacy when combined in a formulation in treating dyslipidemia, the current study aimed to assess the effects of Hamo NK hard capsule on serum lipid profiles of dyslipidemia experimental animals.

\section{METHODS}

\section{Plant materials and preparation of extract}

Ingredients of each hard capsule: Extractum Pericarpium Citri reticulatae perenne siccus (25 mg), Extractum Rhizoma Smilasis ferox siccus (52 mg), Extractum Radix Achyranthis bidentatae siccus (112 mg), Extractum Rhizoma Imperataecylindricae siccus (188mg), Extractum Semen Cassiae torae siccus (64 $\mathrm{mg}$ ), Extractum Flos Styphnolobii japonici imaturi siccus (22mg), Extractum Folium Nelumbinis nuciferae siccus (1mg), Extractum Spica Prunellae siccus (23mg), Extractum Rhizoma Typhonium trilobatum siccus (38 mg).

The materials were in compliance with the standards of Vietnamese Pharmacopoeia V and standard basis ISO/IEC17025 VILLAS 486170 No.10/2019. Grinding and filtering the materials up to a prescribed degree of fragmentation which are controlled on the microbiological safety and Pharmacopoeia $\mathrm{V}$ requirements. The dry extract (extractum siccum) materials were weighed based on the well ratio of the remedy. Afterwards, dry extracts, along with additional pharmaceutical materials are used to produce granulate, and automatic filling of hard capsules with prepared granulate. Granulates are forwarded in the polyethylene bags, and then into the hard capsule. Hamo NK hard capsule was prepared in Tuetinh Institute of Traditional Pharmaco - Medicine. The expected dose in clinical is 4 hard capsules per day (equivalent to $2.1 \mathrm{~g}$ dry extracts per day).

\section{Animals}

- Wistar rats of both sexes, weighed 180 $220 \mathrm{~g}$ provided by The Center of Experimental Animals, DanPhuong, Hanoi.

- Male Swiss mice, weighed 18 - 22 g provided by National Institute of Hygiene and Epidemiology.

The animals were acclimated to housing in the laboratory of the Department of Pharmacology, Hanoi Medical University 7 days before and during the study period; they were fed with standard food and unlimited water intake.

\section{Chemicals}

Propylthiouracil (Rieserstat $\AA$ ) 50mg, Cholesterol (Merk - Germany), Acid Cholic, Poloxamer 407, (Sigma-Singapore), Atorvastatin 10mg (Stellapharm J.V. Co., Ltd), Peanut oil (Vietnam).

Biochemical analyzer ERBA chem. (India) and commercial ERBA diagnostic kits used for serum analysis of total cholesterol (TC), triglyceride (TG), high density lipoprotein cholesterol (HDL - C).

\section{Methods}

\section{Exogenous dyslipidemia model in rats}

Dyslipidemia was induced in rats by oral administration of cholesterol mixture (cholesterol 10\%, cholic acid 1\%, PTU $0.5 \%$ and peanut oil added to precisely $1 \mathrm{~mL}$ ) for 4 
weeks. ${ }^{8,9}$

Wistar Albino rats $(180-220 \mathrm{~g})$ were devived into 5 groups, 10 rats per group. Rats were given per oral twice a day, at least two hours apart:

- Group 1 (normal control group): distilled water $1 \mathrm{~mL} / 100 \mathrm{~g}$ b.w twice a day

- Group 2 (cholesterol control group): cholesterol mixture $10 \mathrm{~mL} / \mathrm{kg}$ b.w/day and then distilled water $1 \mathrm{~mL} / 100 \mathrm{~g}$ b.w

- Group 3 (positive control group): cholesterol mixture $10 \mathrm{~mL} / \mathrm{kg} \mathrm{b.w/day} \mathrm{and} \mathrm{then}$ atorvastatin at the dose of $10 \mathrm{mg} / \mathrm{kg} \mathrm{b.w/day}$

- Group 4 (Hamo NK - low dose): cholesterol mixture $10 \mathrm{~mL} / \mathrm{kg} \mathrm{b.w/day} \mathrm{and} \mathrm{then}$ Hamo NK at the dose of $0.25 \mathrm{~g} / \mathrm{kg} \mathrm{b.w/day}$ (equivalent to clinical dose)

- Group 5 (Hamo NK - high dose): cholesterol mixture $10 \mathrm{~mL} / \mathrm{kg}$ b.w/day and then Hamo NK at the dose of $0.75 \mathrm{~g} / \mathrm{kg} \mathrm{b.w/day} \mathrm{(3}$ times - equivalent to clinical dose)

Rat body weight was recorded at baseline, after 2 weeks and 4 weeks.

On day 15 and day 29, rats were fasted overnight. Blood was collected to measure serum concentrations of TC, TG and HDL - C. LDL - C concentration was calculated using Friedewald formula ${ }^{10}: \mathrm{LDL}-\mathrm{C}=\mathrm{TC}-(\mathrm{HDL}-\mathrm{C})$ - (TG/2.2) (mmol/L).

\section{Endogenous dyslipidemia model in mice}

Poloxamer 407 ( $\mathrm{P}$ - 407) induced dyslipidemia model was described by Millar and et al. ${ }^{11}$ In the experimental design, aninals were randomly divided into five groups of ten animals each.
- Group 1 (normal control group): Mice were given per oral distilled water $1 \mathrm{~mL} / 100 \mathrm{~g}$ b.w/day; then injected IP $0.9 \% \mathrm{NaCl} 10 \mathrm{~mL} / \mathrm{kg}$ b.w on day 7 .

- Group 2 (P - 407 control group): Mice were given per oral distilled water $1 \mathrm{~mL} / 100 \mathrm{~g}$ b.w/day; then injected IP 2\% P - 407 at the dose of $200 \mathrm{mg} / \mathrm{kg}$ b.w on day 7 .

- Group 3 (positive control group): Mice were given per oral atorvastatin at the dose of 100 mg/kg b.w/day; then injected IP 2\% P - 407 at the dose of $200 \mathrm{mg} / \mathrm{kg}$ b.w on day 7 .

- Group 4 (Hamo NK - low dose): Mice were given per oral Hamo NK at the dose of $0.75 \mathrm{~g} / \mathrm{kg} \mathrm{b.w/day} \mathrm{(human} \mathrm{equivalent} \mathrm{dose);}$ then injected i.p 2\% P - 407 at the dose of 200 $\mathrm{mg} / \mathrm{kg}$ b.w on day 7 .

- Group 5 (Hamo NK - high dose): Mice were given per oral Hamo NK at the dose of $1.5 \mathrm{~g} / \mathrm{kg}$ b.w/day (3 times - human equivalent dose); then injected IP 2\% P - 407 at the dose of $200 \mathrm{mg} / \mathrm{kg}$ b.w on day 7 .

Blood was collected at $24 \mathrm{~h}$ after i.p injection of $\mathrm{P}$ - 407 and analysed for serum lipids including TG, TC and HDL - C. Non - HDL - cholesterol (non - HDL - C) was estimated: Non - HDL - C $=\mathrm{TC}-(\mathrm{HDL}-\mathrm{C})$.

\section{Statistical analysis}

All data were shown as mean values and represented as \pm SD. Data were analysed using Microsoft Excel software version 2013. Statistical analysis was done with $\mathrm{t}$ - test and Avant - après test, and $p<0.05$ was considered to be statistically significant.

$p \leq 0.05 \quad p \leq 0.01 \quad p \leq 0.001$

\begin{tabular}{llll}
\hline Compared with the normal control group & $*$ & $* *$ & $* * *$ \\
\hline Compared with the cholesterol control group & + & ++ & +++ \\
\hline
\end{tabular}




\section{RESULTS}

\section{Effects of Hamo NK hard capsule on lipid levels in exogenous dyslipidemia model}

After the first 2 weeks, the rats in all groups gained weights. During the latter half of the experiment, the group treated with Hamo NK at high dose lost weight but there was no significant difference comparing with control group $(p>0.05)$ (Table 1).

Table 1. Effect of Hamo NK hard capsule on body weight gain in dyslipidemia

\begin{tabular}{lcccc}
\hline \multicolumn{1}{c}{ Groups } & $\mathbf{n}$ & $\begin{array}{c}\text { Initial } \\
(\overline{\mathbf{X}} \pm \mathbf{S D} \text {, gram })\end{array}$ & $\begin{array}{c}\text { Week } 2 \\
(\overline{\mathbf{X}} \pm \mathbf{S D}, \mathbf{g r a m})\end{array}$ & $\begin{array}{c}\text { Week 4 } \\
(\overline{\mathbf{X}} \pm \text { SD, gram })\end{array}$ \\
\hline Normal control & 10 & $155.00 \pm 20.68$ & $171.00 \pm 16.63$ & $179.00 \pm 31.43$ \\
\hline Cholesterol control & 10 & $154.50 \pm 18.33$ & $167.00 \pm 33.35$ & $171.00 \pm 30.35$ \\
\hline Atorvastatin 10mg/kg & 10 & $152.00 \pm 23.94$ & $157.00 \pm 16.36$ & $166.00 \pm 17.76$ \\
\hline Hamo NK 0.25g/kg & 10 & $158.00 \pm 14.76$ & $173.00 \pm 30.57$ & $172.00 \pm 30.11$ \\
\hline Hamo NK 0.75g/kg & 10 & $166.00 \pm 18.26$ & $173.00 \pm 16.36$ & $160.50 \pm 20.61$ \\
\hline
\end{tabular}

Table 2 showed that there was no significant difference in the levels of TC, TG, LDL - C and HDL - $\mathrm{C}$ in rats administered atorvastatin or Hamo NK at the two doses compared with the cholesterol control group after 2 weeks of treatment $(p>0.05)$

Table 2. Effect of Hamo NK on lipid levels in cholesterol induced dyslipidemia after 2 weeks of treatment

\begin{tabular}{|c|c|c|c|c|c|}
\hline $\begin{array}{c}\text { Groups/ } \\
\text { treatment 2nd } \\
\text { week }\end{array}$ & $\mathbf{n}$ & $\begin{array}{c}\text { TG } \\
(\bar{X} \pm \mathrm{SD}, \mathrm{mmol} / \mathrm{L})\end{array}$ & $\begin{array}{c}\text { TC } \\
(\bar{X} \pm \mathrm{SD}, \mathrm{mmol} / \mathrm{L})\end{array}$ & $\begin{array}{c}\text { HDL - C } \\
(\bar{X} \pm \mathrm{SD}, \mathrm{mmol} / \mathrm{L}\end{array}$ & $\begin{array}{c}\text { LDL - C } \\
-(\bar{X} \pm \mathrm{SD}, \mathrm{mmol} / \mathrm{L})\end{array}$ \\
\hline Normal control & 10 & $1.31 \pm 0.32$ & $2.23 \pm 0.22$ & $0.99 \pm 0.18$ & $0.64 \pm 0.17$ \\
\hline $\begin{array}{l}\text { Cholesterol } \\
\text { control }\end{array}$ & 10 & $1.51 \pm 0.32$ & $2.60 \pm 0.37$ & $1.04 \pm 0.24$ & $0.87 \pm 0.26^{*}$ \\
\hline $\begin{array}{l}\text { Atorvastatin } \\
10 \mathrm{mg} / \mathrm{kg}\end{array}$ & 10 & $\begin{array}{c}1.58 \pm 0.40 \\
(4.6 \%)\end{array}$ & $\begin{array}{c}2.38 \pm 0.27 \\
(\downarrow 8.5 \%)\end{array}$ & $\begin{array}{c}1.05 \pm 0.18 \\
(\uparrow 0.9 \%)\end{array}$ & $\begin{array}{c}0.61 \pm 0.27 \\
(\downarrow 29.9 \%)\end{array}$ \\
\hline $\begin{array}{l}\text { Hamo NK } 0.25 \\
\mathrm{~g} / \mathrm{kg}\end{array}$ & 10 & $\begin{array}{c}1.61 \pm 0.56 \\
(\uparrow 1.9 \%)\end{array}$ & $\begin{array}{c}2.59 \pm 0.36 \\
(\downarrow 0.4 \%)\end{array}$ & $\begin{array}{c}1.00 \pm 0.20 \\
(\downarrow 3.8 \%)\end{array}$ & $\begin{array}{c}0.86 \pm 0.31 \\
(\uparrow 1.1 \%)\end{array}$ \\
\hline $\begin{array}{l}\text { Hamo NK } 0.75 \\
\mathrm{~g} / \mathrm{kg}\end{array}$ & 10 & $\begin{array}{c}1.52 \pm 0.42 \\
(\uparrow 0.7 \%)\end{array}$ & $\begin{array}{c}2.37 \pm 0.22 \\
(\downarrow 8.8 \%)\end{array}$ & $\begin{array}{c}0.92 \pm 0.09 \\
(\downarrow 11.5 \%)\end{array}$ & $\begin{array}{c}0.75 \pm 0.17 \\
(\downarrow 13.8 \%)\end{array}$ \\
\hline
\end{tabular}

Figure 1 showed that after 4 weeks of treatment, the groups treated with atorvastatin had lower levels of LDL - C and TC than that of the cholesterol control group. The LDL - C levels was a significant attenuated by administration of different doses of Hamo NK $(0.25 \mathrm{~g} / \mathrm{kg}$ and $0.75 \mathrm{~g} / \mathrm{kg})$ shown in Figure 1, while the TG, TC and HDL - C levels were not statistically considerable changes compared to the cholesterol control group. 


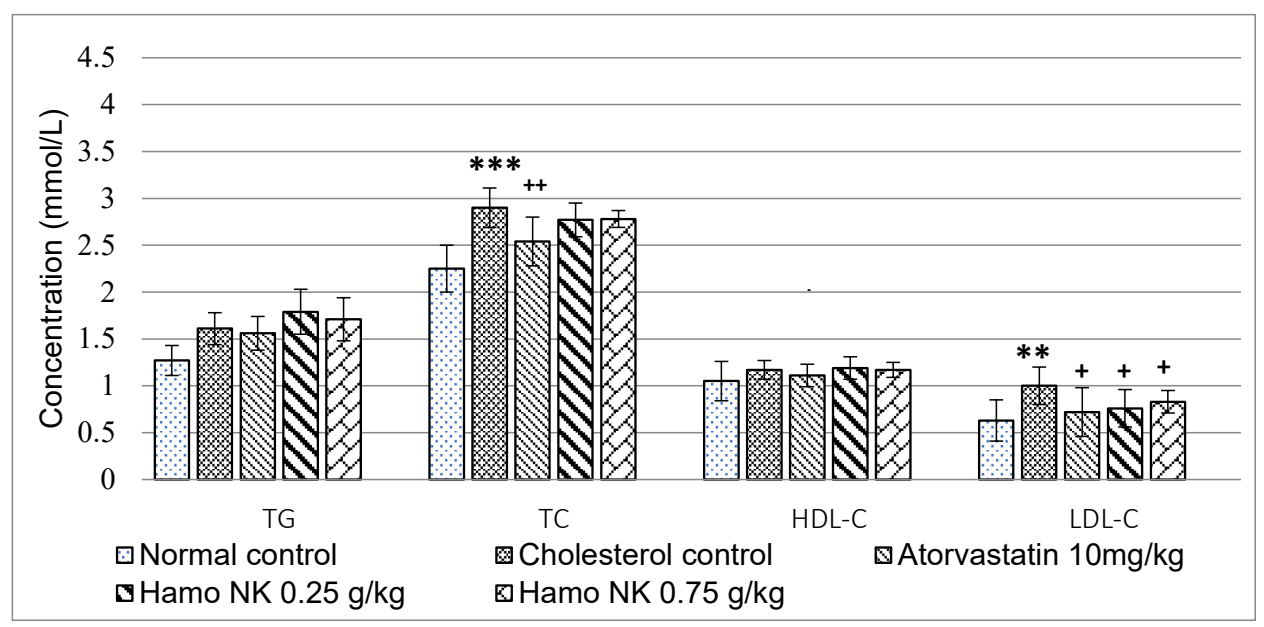

Figure 1. Changes in the serum lipid concentration of animals in cholesterol induced dyslipidemia after 4 weeks

Note: Statistical analysis was done with $t$ - test and Avant - après test, and $p<0.05$ was considered to be statistically significant; *: vs normal control; +: vs cholesterol control: $p<0.05: * /+; p<0.01$ : **/++; and $p<0.001:{ }^{* *} /+++$

\section{Effects of Hamo NK on lipid levels in Poloxamer 407 induced dyslipidemia.}

The results obtained from the model of experimental mice in the Table 3 showed that the serum lipid levels were significant elevation in $\mathrm{P}-407$ control as compared to normal control $(p<0.001)$. (Table 3)

Table 3. Hyperlipidemia model induced by $P$ - 407

\begin{tabular}{lccc}
\hline \multicolumn{1}{c}{ Lipid levels (mmol/l) } & $\mathbf{n}$ & $\begin{array}{c}\text { Normal control } \\
(\overline{\boldsymbol{X}} \pm \mathbf{S D}, \mathbf{m m o l} / \mathbf{L})\end{array}$ & $\begin{array}{c}\text { Poloxamer } 407 \text { control } \\
(\overline{\boldsymbol{X}} \pm \mathbf{S D}, \mathbf{m m o l} / \mathbf{L})\end{array}$ \\
\hline TC & 10 & $4.18 \pm 1.12$ & $9.93 \pm 1.10^{* * *}$ \\
\hline TG & 10 & $0.97 \pm 0.16$ & $8.19 \pm 2.65^{* * *}$ \\
\hline HDL - C & 10 & $0.80 \pm 0.23$ & $1.52 \pm 0.40^{* * *}$ \\
\hline non - HDL - C & 10 & $3.38 \pm 1.03$ & $8.41 \pm 1.29^{* * *}$ \\
\hline
\end{tabular}

Note: ${ }^{* * *}: p<0.001$ was significant changes compared to control

The table 4 showed that there was a substantial reduction in TC and non - HDL - C, and increase in HDL - C level in treated statin group as compared to $\mathrm{P}-407$ control. Hamo NK $1.5 \mathrm{~g} / \mathrm{kg}$ b.w showed significant decrease in TC and non - HDL - C when compare to P - 407 control group. The lipid concentrations in group treated Hamo NK at the dose of $0.5 \mathrm{~g} / \mathrm{kg}$ did not change compared to the P - 407 control group. 
Table 4. Effect of Hamo NK on lipid levels in Poloxamer 407 induced dyslipidemia

\begin{tabular}{|c|c|c|c|c|c|}
\hline \multirow[b]{2}{*}{ Groups } & \multirow[b]{2}{*}{$\mathbf{n}$} & \multicolumn{4}{|c|}{ Serum lipid levels ( \pm SD, mmol/L) } \\
\hline & & $\begin{array}{c}\text { TG } \\
(\mathrm{mmol} / \mathrm{L})\end{array}$ & $\begin{array}{c}\mathrm{TC} \\
(\mathrm{mmol} / \mathrm{L})\end{array}$ & $\begin{array}{l}\text { HDL - C } \\
(\mathrm{mmol} / \mathrm{L})\end{array}$ & $\begin{array}{c}\text { Non - HDL - C } \\
(\mathrm{mmol} / \mathrm{L})\end{array}$ \\
\hline Normal control & 10 & $0.97 \pm 0.16$ & $4.18 \pm 1.12$ & $0.80 \pm 0.23$ & $3.38 \pm 1.03$ \\
\hline P - 407 control & 10 & $8.19 \pm 2.65^{* * *}$ & $9.93 \pm 1.10^{* * *}$ & $1.52 \pm 0.40^{* * *}$ & $8.41 \pm 1.29^{* * *}$ \\
\hline $\begin{array}{l}\text { Atorvastatin 100mg/ } \\
\mathrm{kg}\end{array}$ & 10 & $\begin{array}{l}9.8 \pm 3.29 \\
(19.7 \%)\end{array}$ & $\begin{array}{l}7.68 \pm 2.13++ \\
(\downarrow 22.7 \%)\end{array}$ & $\begin{array}{l}2.02 \pm 0.69+ \\
(32.9 \%)\end{array}$ & $\begin{array}{l}5.66 \pm 1.87++ \\
(\downarrow 32.7 \%)\end{array}$ \\
\hline $\begin{array}{l}\text { Hamo NK } \\
0.5 \mathrm{~g} / \mathrm{kg}\end{array}$ & 10 & $\begin{array}{l}8.35 \pm 2.55 \\
(1.95 \%)\end{array}$ & $\begin{array}{l}10.46 \pm 2.57 \\
(5.34 \%)\end{array}$ & $\begin{array}{l}1.72 \pm 0.44 \\
(13.2 \%)\end{array}$ & $\begin{array}{l}8.74 \pm 2.27 \\
(3.92 \%)\end{array}$ \\
\hline Hamo NK 1,5 g/kg & 10 & $\begin{array}{l}8.67 \pm 2.41 \\
(5.86 \%)\end{array}$ & $\begin{array}{l}7.66 \pm 0.74+++ \\
(\downarrow 22.9 \%)\end{array}$ & $\begin{array}{l}1.60 \pm 0.26 \\
(\uparrow 5.3 \%)\end{array}$ & $\begin{array}{l}6.06 \pm 0.80+++ \\
(\downarrow 27.9 \%)\end{array}$ \\
\hline
\end{tabular}

Note: Statistically analysis was done with $t$ - test and Avant - après test, and $p<0.05$ was considered to be statistically significant; +: vs cholesterol control: $p<0.05$ : +; $p<0.01$ : ++; and $p<0.001$ : +++

\section{DISCUSSION}

Hypercholesterolemia accompanied by high serum lipoproteins and low HDL - $\mathrm{C}$ is a main factor for the development of atherosclerotic disease. ${ }^{12}$ Excess diet - derived cholesterol is the primary cause for hypercholesterolemia. These conditions can affect lipoprotein metabolism; increase body weight; elevates TC, TG and LDL - C levels and reduce HDL - C level in serum. The model of exogenous dyslipidemia which induced by oil - cholesterol mixture (cholesterol with bile acid and hypothyroidism - inducing agents) is widely used to screen natural or synthetic drugs. Based on the successful model, we evaluated the effects of Hamo NK hard capsule on the changes of lipid levels.

As shown in table 1, increasing weight was seen in groups which were possibly caused by the accumulation of fat in the body. These findings are consistent with the results of a previous study which showed a rapid increase in the body weight of rats fed a high - cholesterol diet over 4 weeks. ${ }^{13}$ In contrast, the group treated with Hamo NK at the dose of $0.75 \mathrm{~g} / \mathrm{kg}$ b.w/day slightly decreased the final body weight. This may be a benefit for treatment dyslipidemia combined obesity. Additionally, rats that consumed a cholesterol enrich diet exhibited increased plasma lipid levels, including TC and LDL - C levels, in which the effect of Hamo NK hard capsule on LDL C concentration was observed after 4 weeks. Hamo NK at high dose had the similar effect on LDL - C level compare group treatment with atorvastatin.

These effects of Hamo NK hard capsule are a combination of some herbal medicines which improve lipid metabolism. The triterpenoid and alkaloid from Folium nelumbinis nuciferae have also reported a concentration - dependent inhibition of the activities of alpha - amylase and lipase, inhibited absorption of lipids and carbohydrates, accelerated lipid metabolism and up - regulated energy. ${ }^{14}$ According Meiling Zhang et al (2018) suggested that Imperata cylindrica L. does not impair cholesterol absorption directly. The treated mice had decrease cholesterol indirectly probably due to decrease cholesterol absorption rate or the use of triglyceride. ${ }^{6}$ Pericarpium Citrireticulatae perenne consists of flavonoids (narirutin, 
hesperidin, didymin, nobiletin, tangeretin, $3,5,6,7,8,3^{\prime}, 4^{\prime}$ - heptemthoxyflavone) could significantly decrease the content of TC, LDL - $C$ of hyperlipemia rats induced by fat emulsion. ${ }^{5}$ Heart fatty acid-binding protein $(\mathrm{H}-\mathrm{FABP})$ and cutaneous fatty acid-binding protein(C - FABP) are thought to play key roles in fatty acid metabolism, such as fatty acid storage and transport. Hesperidin may improve hypercholesterolemia and fatty liver by inhibiting cholesterol synthesis and absorption, regulating $\mathrm{RBP}, \mathrm{C}$ - FABP and $\mathrm{H}$ - FABP mRNA expression. ${ }^{15}$ Furthermore,ZhouTdemonstrated flavonoids like quercetin, isoquercitrin, catechin, hyperoside, and astragalin from Lotus leaf was orally administered once a day for 28 days, the results showed that serum TC and TG levels were significantly decreased, whereas serum HDL - C level were increased. ${ }^{14}$

A model of endogenous hyperlipidemia was developed by intraperitoneal (i.p) injection of $\mathrm{P}$ - $407200 \mathrm{mg} / \mathrm{kg}$ b.w. $\mathrm{P}$ - 407, which is a polyether - based nonionic surface - active - agent (surfactant), provides an attactived means of inducing hyperlipidemia because of its rapid onset and seeming lack of over toxicity as compare with Triton WR - 1339. $\mathrm{P}$ - 407 has been known to cause significant dose - dependent hypercholesterolemia and hypertriglyceridemia in rats and mice by several mechanisms (inhibition of lipoprotein lipase, indirect stimulation of HMG - CoA (3 - hydroxy 3 - methylglutaryl Co - A) reductase, promotion of concentration of hepatic cholesterol content, etc.). ${ }^{16}$ Based on its mechanism and shreds of evidence of efficiency, statin is chosen as the drug reference standard. It inhibits HMG - CoA reductase, which counters the effect of $\mathrm{P}-407$, thus decreases the serum TC. In addition, it also lowers the level of LDL by lowering the level of its precursor (VLDL and IDL), which further enhances its lipid - lowering effect. Currently, seven different statins are available generically, but only atorvastatin and rosuvastatin are used in high - intensit therapy. ${ }^{4}$

Because of its safeness, various $P-407$ induced hyperlipidemia models in rats and mice have been conducted often with the standard dose $0.5 \mathrm{~g} / \mathrm{kg}$. In this study, the dose of $0.2 \mathrm{~g} / \mathrm{kg}$ was chosen in order to evaluate and compare the effects of the regimens more easily. Within $24 \mathrm{~h}$ of its i.p injection a profound hyperlipidemia state is achieved. The results (table 3 ) showed that the triglyceride concentration increased substantially by 8.4 - fold, TC levels and non - HDL - C concentrations increased by 2.4 fold; 2.5 - fold. Base on the successful inducing hyperlipidemia in the model group by $\mathrm{P}-407$, effects of Hamo NK could be survey. The data indicated that the levels of TC and Non - HDL C concentrations were significantly lowered, in dyslipidemia mice treated with Hamo NK (1.5g/ $\mathrm{kg} /$ day). Both dose of Hamo NK were slightly increasing the serum HDL - C level. Mechanisms of compounds in the treatment of Hamo NK are very complex. The study of Semen Cassiae showed that the administration of Semen Cassiae decreased levels of LDL - C, and increased the levels of HDL - C. ${ }^{17}$ The presence of flavonoids such as quercetin in the leaves of Folium nelumbinis nuciferae and in Semen Cassiae indicative of inhibition of cholesterol biosynthesis by inhibition of HMG Co - A. This enzyme plays a key role in controlling lipid levels in plasma and other tissue. ${ }^{14}$ In addition, the expression of cholesterol $7 \alpha$ - hydroxylase $(\mathrm{C} 7 \alpha \mathrm{H})$, a critical enzyme in the conversion of cholesterol to bile acids was significant elevated by urosonic acid and quercetin. 


\section{CONCLUSION}

In conclusion, our results suggested that oral administration of Hamo NK hard capsule at high dose $(1.5 \mathrm{~g} / \mathrm{kg})$ reduced TC and non HDL - C concentrations in hyperlipidemic mice induced by $\mathrm{P}-407$.

Utilizing exogenous model induced by oil - cholesterol mixture, Hamo NK hard capsule at high dose $(0.75 \mathrm{~g} / \mathrm{kg} \mathrm{b.w})$ was shown to be effective in significantly lowering LDL - C levels in rats.

\section{REFERENCES}

1. Che C - T, Wanzg ZJ, Chow MSS, Lam CWK. Herb - Herb Combination for Therapeutic Enhancement and Advancement: Theory, Practice and Future Perspectives. Molecules. 2013; 18(5):5125 - 5141. doi:10.3390/ molecules 18055125

2. Welz AN, Emberger - Klein A, Menrad $K$. Why people use herbal medicine: insights from a focus - group study in Germany. BMC Complement Altern Med. 2018;18. doi:10.1186/ s12906 - 018 - 2160 - 6

3. Rader DJ, Hobbs. Disorders of lipoprotein metabolism. In: HH Harrisons's Principles of Internal Medicine. 20th edition. New York: McGraw - Hill.

4. Golomb BA, Evans MA. Statin Adverse Effects: A Review of the Literature and Evidence for a Mitochondrial Mechanism. Am J Cardiovasc Drugs Drugs Devices Interv. 2008; 8(6):373 - 418.

5. Jj Y, J S, Mq Y, Zh L, Gy L. Correlation between lipid - lowering efficacy and components of Pericarpium Citri Reticulatae. Zhongguo Zhong Yao Za Zhi Zhongguo Zhongyao Zazhi China J Chin Mater Medica. 2019; 44(15):3335 - 3342. doi:10.19540/j.cnki. cjcmm.20190523.304

6. Effects of Imperata cylindricaPolysaccharides on Glucose and Lipid Metabolism in Diabetic Mice. Food Science 2012(19). Accessed August 4, 2020. http://en.cnki.com.cn/Article_en/ CJFDTOTAL - SPKX201219064.htm

7. Ming Guo, Yue Liu, Zhu - Ye Gao, Da - zhuo Sh. Chinese Herbal Medicine on Dyslipidemia: Progress and Perpective. Evidence - Based Complementary and Alternative Medicine. 2014; 2014.

8. Nassiri - AsI M, Zamansoltani F, Abbasi E, Daneshi MM, Zangivand AA. Effects of Urtica dioica extract on lipid profile in hypercholesterolemia rats. Journal of Chinese Integrative Medicine. 2009; 7(5):428433. doi: 10.3736/jcim20090506

9. Thanh Phuong Nguyen. Study on toxicity and effect of regulating dyslipidemia of Monacholes on experimental. 2011.

10. Friedewald WT, Levy RI, Fredrickson DS. Estimation of the concentration of low - density lipoprotein cholesterol in plasma, without use of the preparative ultracentrifuge. Clin Chem. 1972; 18(6):499 - 502.

11. Millar JS, Cromley DA, McCoy MG, Rader DJ, Billheimer JT. Determining hepatic triglyceride production in mice: comparison of poloxamer 407 with Triton WR - 1339. J Lipid Res. 2005;46(9):2023 - 2028. doi:10.1194/jlr. D500019 - JLR200

12. The Role of Lipids and Lipoproteins in Atherosclerosis - Endotext - NCBI Bookshelf. Accessed August 6, 2020. https://www.ncbi. nlm.nih.gov/books/NBK343489/

13. Mir Hakima, Krouf Djamil, Taleb - Dida Nawal, Berzou Sadia, Guenzet Akila, Khelladi HadjMostefa. Effects of citrus latifolia extract on dyslipidemia and tissues redox status in rats fed a high - cholesterol diet. Nutr Food Sci. 2019;49(6):989 - 999. doi:10.1108/NFS - 04 $2018-0110$

14. Zhou T, Luo D, Li X, Luo Y. Hypoglycemic 
and hypolipidemic effects of flavonoids from lotus (Nelumbo nuficera Gaertn) leaf in diabetic mice. Journal of Medicinal Plant Research. 2009; 3(4):290 - 293.

15. Xiong H, Wang J, Ran Q, et al. Hesperidin: A Therapeutic Agent For Obesity. Drug Design, Development and Therapy. doi:10.2147/DDDT. S227499

16. Johnston TP, Korolenko TA, Sahebkar A. P - 407 - induced Mouse Model of Dose - controlled Hyperlipidemia and Atherosclerosis: 25 Years Later. J Cardiovasc Pharmacol. 2017; 70(5):339 - 352. doi:10.1097/ FJC.0000000000000522

17. Zhang M, Li X, Liang $H$, et al. Semen Cassiae Extract Improves Glucose Metabolism by Promoting GIUT4 Translocation in the Skeletal Muscle of Diabetic Rats. Front Pharmacol. 2018;9. doi:10.3389/fphar.2018.00235 